This item was submitted to Loughborough's Research Repository by the author.

Items in Figshare are protected by copyright, with all rights reserved, unless otherwise indicated.

\title{
Television viewing and risk of mortality: exploring the biological plausibility
}

\section{PLEASE CITE THE PUBLISHED VERSION}

https://doi.org/10.1016/j.atherosclerosis.2017.06.024

\section{PUBLISHER}

(c) Elsevier

\section{VERSION}

AM (Accepted Manuscript)

\section{PUBLISHER STATEMENT}

This work is made available according to the conditions of the Creative Commons Attribution-NonCommercialNoDerivatives 4.0 International (CC BY-NC-ND 4.0) licence. Full details of this licence are available at: https://creativecommons.org/licenses/by-nc-nd/4.0/

\section{LICENCE}

CC BY-NC-ND 4.0

\section{REPOSITORY RECORD}

Hamer, Mark, Thomas E. Yates, and Panayotes Demakakos. 2019. "Television Viewing and Risk of Mortality: Exploring the Biological Plausibility”. figshare. https://hdl.handle.net/2134/25402. 
Television viewing and risk of mortality: exploring the biological plausibility

Mark Hamer, ${ }^{1,2,3} \mathrm{PhD}$, Thomas Yates, ${ }^{3,4} \mathrm{PhD}$, Panayotes Demakakos, ${ }^{2} \mathrm{PhD}$

${ }^{1}$ School Sport, Exercise \& Health Sciences, National Centre for Sport and Exercise Medicine - East Midlands, Loughborough University, Loughborough LE11 3TU, United Kingdom.

${ }^{2}$ Department of Epidemiology and Public Health, University College London, London.

${ }^{3}$ NIHR Leicester Biomedical Research Centre

${ }^{4}$ University of Leicester, Diabetes Research Centre, Leicester Diabetes Centre, Leicester General Hospital

Correspondence: Prof Mark Hamer, National Centre for Sport and Exercise Medicine - East Midlands, Loughborough University, Loughborough LE11 3TU, United Kingdom. Email: m.hamer@lboro.ac.uk

Total Word count $=2,023$ 


\section{Abstract}

Background and aims: Television (TV) viewing is a major component of leisure sedentary time, and has been consistently associated with cardiovascular disease. We examined the extent to which metabolic biomarkers explain the association between TV viewing and mortality.

Methods: Participants ( $N=8,451$, aged $64.8 \pm 9.9$ yrs) were drawn from The English Longitudinal Study of Ageing (ELSA), a national prospective cohort study of community-dwelling men and women living in England. The individual participant data were linked with death records from the National Health Service registries from 2008 to 2012. Cox proportional hazards models were used to estimate the risk of death according to time spent watching TV, with biomarkers added in a step wise fashion to estimate potential mediation.

Results: Over an average follow up of 4 years (33,832 person years) there were 370 deaths. In models adjusted for comorbidities, psychosocial factors, and health behaviours including physical activity, there was an association between TV viewing and mortality ( $\geq 6 \mathrm{hrs}$ per day vs. $<2 \mathrm{hrs}$ per day [Ref]; Hazard ratio $=1.98,95 \% \mathrm{Cl}, 1.25,3.15)$. Adjustment for inflammatory markers (C-reactive protein and fibrinogen) accounted for $\sim 15.7 \%$ of the association between TV viewing and mortality, but metabolic risk factors (HDL-cholesterol, triglycerides, glycated haemoglobin) did not contribute.

Conclusion: The association between TV viewing and mortality was partly mediated by inflammatory markers, although the relationship remains largely unexplained.

Key words: Sedentary; Ageing; Mortality; Inflammation; Biomarkers 


\section{Introduction}

Television (TV) viewing is a major component of leisure sedentary time, and has been consistently associated with cardiovascular disease (CVD) and mortality in population cohort studies. ${ }^{1-5}$ Sedentary behaviour has been conceptualised as a distinct domain of behaviour, which may pose a risk to health independently of physical activity. High levels of physical activity appear to partly attenuate associations between TV time and mortality, ${ }^{1}$ but it is unclear whether the underlying mechanisms of this association are different than those described in the physical activity literature. Inflammatory and haemostatic risk factors, and blood pressure appear to explain the greatest proportion of the inverse association between physical activity and CVD events, ${ }^{6,7}$ but the mechanisms explaining the association between TV viewing and mortality remain poorly described.

Previous studies have explored associations of TV viewing with changes in inflammatory and metabolic risk factors although results have often been inconsistent, ${ }^{8-13}$ and these studies did not include follow-up of mortality to examine mediation effects. The main aim of this study was to examine the extent to which inflammatory and metabolic biomarkers explain the association between TV viewing and mortality in a sample of community dwelling older men and women. 


\section{Materials and Methods}

\section{Study sample and procedures}

The English Longitudinal Study of Ageing (ELSA) is a cohort study of older adults previously described. ${ }^{14}$ Data on TV viewing was first collected at wave $4(2008 / 9)$, and was thus used as the baseline for the present analyses. The individual participant data were linked with death records from National Health Service registries for all consenting respondents $(96.5 \%$ of the sample) up to February 2012, and primary cause of death were based on the International Classification of Diseases, Ninth (ICD-9) and Tenth (ICD-10) Revisions. Codes corresponding to CVD mortality were 390-459 for ICD-9 and I01-199 for ICD-10 and cancer mortality were 140-239 for ICD-9 and C00-D48 for ICD-10. Participants with clotting and bleeding disorders, or taking anti-coagulant medication were excluded from providing blood. Participants gave full informed consent to participate in the study. Ethical approval was obtained from the London Multi-center Research Ethics Committee, compliant with the Declaration of Helsinki.

\section{Baseline TV viewing and physical activity}

Television viewing was assessed from self report as previously described. ${ }^{11,15}$ The measure of TV viewing time was validated in 105 (55 men, 50 women) ELSA participants (aged $66.3 \pm 6.5$ yrs) using objective accelerometry devices (unpublished data). Participants wore a GeneActiv device on their wrist for seven consecutive days. The categorical TV exposure variable described above was weakly correlated with objectively assessed hours per day of sedentary time $(r=0.24, p=0.014)$, which might reflect the fact TV only represents a proportion of overall sedentary time. The questions on TV viewing were administered two years later in the whole cohort and moderate reliability was observed (Pearson's $r=0.55$, $p<0.001)$. 
Participants were asked how often (> once a week, once a week, $1-3$ times a month, and hardly ever/never) they took part in vigorous, moderate- and low-intensity physical activity. Prompt cards were used to assist participants in the interpretation of physical activity intensities. The physical activity and TV viewing measures used in ELSA have demonstrated convergent validity in relation to psychosocial, physical and biochemical risk factors in previous work. $^{15-18}$

\section{Clinical assessments}

Nurses collected anthropometric data (weight, height), and blood samples. Body weight was measured without shoes and in light clothing using Tanita electronic scales, and height was measured using a Stadiometer with the Frankfort plane in the horizontal position. Body mass index (BMI) was calculated using the standard formula [weight (kilograms)/height (meters) squared]. Systolic and diastolic blood pressure was measured with an Omron HEM907 monitor and an average of the second and third recordings was used for the present analyses. Blood samples were analyzed for several biomarkers, including high sensitivity Creactive protein [CRP], fibrinogen, HDL-cholesterol, triglycerides, glycated haemoglobin. The samples were analysed at the Royal Victoria Infirmary (Newcastle-upon-Tyne, UK), described elsewhere. ${ }^{19}$

\section{Covariates}

Trained interviewers asked questions on cigarette smoking (current, ex-smoker or nonsmoker), alcohol intake (categorised as; at least five times a week, at least once a week, monthly, rarely/never), chronic illnesses (at least one vs. none), and depressive symptoms (using the 8-item Centre of Epidemiological Studies Depression scale ${ }^{20}$ ). Disability was 
denoted as reporting difficulties in one or more activities from questions on perceived difficulties in six basic activities (e.g. difficulty dressing) and seven instrumental activities of daily living (e.g. difficulty preparing a hot meal). ${ }^{21}$

\section{Statistical analysis}

We used Cox proportional hazards regression models to examine associations between TV viewing and death. Years were the time scale for the follow-up calculated from age at death, and for participants with no record of an event, the data were censored at February 2012. Plots of the Nelson-Aalen cumulative hazard estimates were examined to assess the proportional hazards assumption. The exposure variable was treated as a categorical variable in the main analyses but models were also run with TV viewing as a continuous variable using the standardised score ( $1 \mathrm{SD}=4.2 \mathrm{hrs} / \mathrm{d}$ TV viewing). We estimated models that initially contained the covariates age and sex (model 1), with further adjustment for physical activity, smoking, alcohol intake, depressive symptoms (CES-D>3), long standing illness, disability (model 2). These covariates were considered as confounders and selected a priori based on previous literature. ${ }^{1,11,17}$ Sensitivity analyses were conducted removing deaths in the first year of follow up. In order to test for biological mediation we separately added inflammatory markers (log CRP, fibrinogen) and metabolic risk factors (HDLcholesterol, triglycerides, glycated haemoglobin) into the models, all as continuous variables. BMI (as a categorical variable; $<25 ; 25-29.99 ; \geq 30 \mathrm{~kg} / \mathrm{m}^{2}$ ) was added as a covariate in these models as it remains unclear if adiposity lies on the causal pathway from TV viewing to mortality or acts as a predisposing factor to sedentary behaviour. ${ }^{22}$ Mediation 
was calculated from percentage changes in coefficients (In HR). ${ }^{6}$ All analyses were conducted using SPSS version 22 (SPSS, Chicago, IL).

\section{Results}

A sample size of 9,126 provided complete data on time spent TV viewing, although 357 participants did not provide consent to mortality linkage and a further 318 had missing data on other covariates leaving a final analytic sample of 8,451 . There were no differences between participants excluded and the analytic sample. Biomarker data were available in a sub-sample of participants that completed the health examination $(n=5,033)$.

The baseline characteristics of the sample are shown in Table 1. High levels of TV viewing ( $>6 \mathrm{hr} / \mathrm{d}$ ) were reported in $29.1 \%$ of participants. Participants viewing high levels of TV were more likely to be female, smokers, undertake little vigorous exercise, report chronic illness, depression, and disability. Participants in the highest TV viewing category were also more likely to be obese and display a less favourable biomarker profile.

Over an average follow up of 4 years there were 370 deaths (78 CVD; 91 cancer). In models adjusted for comorbidities, psychosocial factors, and health behaviours including physical activity, there was an association between TV viewing and mortality (see Table 2). When the exposure data were treated continuously there was an association between TV (per SD unit increase) and mortality (fully adjusted $\mathrm{HR}=1.17,95 \% \mathrm{Cl}, 1.06,1.28$ ). In sensitivity analyses the results remained unchanged after removal of 72 deaths in first year of follow up (Table 2; Model 3). In analyses examining cause specific deaths the point estimates for CVD (fully adjusted $\mathrm{HR}$ per SD unit $=1.22,95 \% \mathrm{Cl}, 1.00,1.49$ ) and cancer (fully adjusted $\mathrm{HR}$ per unit $=$ 
$1.16,95 \% \mathrm{Cl}, 0.96,1.39)$ were similar to those of all-cause mortality albeit with wider confidence intervals owing to lower numbers of deaths.

We examined associations between biomarkers and mortality (Table 3). In models mutually adjusted for all biomarkers and BMI, fibrinogen $(p<0.001)$ was most strongly predictive of mortality, whilst HDL-cholesterol $(p=0.087)$ and CRP $(p=0.061)$ reached marginal significance. Biological mediation was examined by separately adding inflammatory markers (CRP, fibrinogen) and metabolic risk factors (HDL-cholesterol, triglycerides, glycated haemoglobin) into the models of TV viewing and mortality (Table 4). The addition of inflammatory markers (C-reactive protein and fibrinogen) into the models accounted for $\sim 15.7 \%$ of the association between TV viewing and mortality, although no attenuation in effect estimates were observed when metabolic risk factors (HDL-cholesterol, triglycerides, glycated haemoglobin) were added. We repeated these analyses using CVD death as the outcome and results were similar (Table 4).

\section{Discussion}

The main aim was to examine the extent to which biological risk factors mediate the association between TV viewing and mortality. We replicated previous studies ${ }^{1}$ by demonstrating an association between TV viewing and mortality. We further demonstrated the novel finding that this association was partly mediated by inflammatory markers. Demonstrating biological plausibility is important to understand the causal nature of an association. ${ }^{23}$ However, the association between TV viewing and mortality remained largely unexplained using the biomarkers available in this study. 
Sedentary behaviours such as TV viewing are characterised by a lack of muscle contraction. Muscle tissue expresses various transcriptional co-activators such as PGC1 $\alpha$, which lead to a transient release of myokines (during exercise) that may promote systemic antiinflammatory effects. ${ }^{24}$ Research has demonstrated that prolonged sitting is associated with the expression of various genes linked to inflammatory responses. ${ }^{25}$ Fibrinogen, the strongest predictor of mortality in the present study, may also have relevance in terms of elevated risk of vascular conditions, particularly venous thrombosis. Recent experimental data demonstrated increases in plasma fibrinogen with prolonged uninterrupted sitting that was attenuated with active breaks. ${ }^{26}$ Excess TV viewing may reflect chronic energy imbalance indicated by excess adiposity and metabolic disorders, ${ }^{27}$ although in the present study classic metabolic risk factors did not explain the link between TV viewing and mortality. Recent evidence has suggested that physical inactivity may be a consequence of obesity, ${ }^{22}$ which may explain why the associated metabolic disorders are not on the causal pathways linking sedentary behaviours with disease outcomes. Since conventional risk factors appear to loose predictive power in older populations, novel biomarkers ${ }^{28}$ may have been more relevant in the present cohort and explained a greater proportion of association between TV and mortality.

TV viewing was measured at the same time point as the biomarkers, thus we cannot establish the precise nature of the temporal relationship between these factors. Nevertheless, previously published data from ELSA has demonstrated a prospective association between TV viewing and change in inflammatory markers. ${ }^{11}$ Our analysis 
supports the main criteria for mediation, that is, the key exposure (TV viewing) was associated with biomarkers (potential mediators), the potential mediators predicted outcome (mortality), and exposure predicted outcome; this association was attenuated after adjustment for the mediators (inflammatory markers).

Our study has some notable strengths, including the use of a large national sample of community-dwelling men and women; the inclusion of a wide range of potential biological mediators; and adjustment for important confounding factors. There are also some limitations. Our measure of sedentary behavior was limited to leisure TV viewing thus our results cannot be generalized to total sedentary time or sitting. Albeit in this older sample of adults it is likely that TV viewing is still by far the most predominant screen based activity. ${ }^{29}$ Nevertheless, our TV exposure measure was validated against objectively assessed sedentary time and also demonstrated reliability over repeated assessments. Previous studies have suggested questions that focus on TV viewing have demonstrated the strongest reliability and validity among non-occupational sedentary behaviour questions. ${ }^{30}$ It was not possible to adjust models for diet, as such data were not collected. However, recent data has suggested that snack food and TV viewing were independently associated with metabolic syndrome. ${ }^{31}$ The biomarkers were only collected once at baseline although variables such as CRP have demonstrated acceptable stability over long term follow-up. ${ }^{32}$ Our follow-up period was relatively short and reverse causation cannot be ruled out, although in sensitivity analyses the results remained unchanged after removal of deaths in the first year of follow up. Despite the relatively short follow-up it is likely that TV viewing reflects a habitual behaviour across the lifecourse. ${ }^{33}$ Existing evidence suggests TV viewing 
may be associated with certain types of cancers, ${ }^{34}$ although we were unable to sub-type specific cancers owing to lack of events.

In conclusion, the association between TV viewing and mortality was partly mediated by inflammatory markers, although the relationship remains largely unexplained. 


\section{Conflict of interest}

None of the authors have any competing interests to declare.

\section{Funding sources}

The data were made available through the UK Data Archive. Hamer and Yates acknowledge support from the National Institute for Health Research (NIHR) Leicester Biomedical Research Centre, which is a partnership between University Hospitals of Leicester NHS Trust, Loughborough University and the University of Leicester. The ELSA funders had no role in the study design; in the collection, analysis and interpretation of data; in writing of the report; or in the decision to submit the paper for publication. The developers and funders of ELSA and the Archive do not bear any responsibility for the analyses or interpretations presented here.

\section{Author contributions}

Hamer had full access to the data, and takes responsibility for the integrity and accuracy of the results. Hamer drafted the paper, performed analyses and designed the study. Yates and Demakakos contributed to the concept and design of the study and critical revision of the manuscript. 


\section{References}

1. Ekelund U, Steene-Johannessen J, Brown WJ, Fagerland MW, Owen N, Powell KE, Bauman A, Lee IM; Lancet Physical Activity Series 2 Executive Committe.; Lancet Sedentary Behaviour Working Group. Does physical activity attenuate, or even eliminate, the detrimental association of sitting time with mortality? A harmonised meta-analysis of data from more than 1 million men and women. Lancet. 2016;388(10051):1302-10.

2. Stamatakis E, Hamer M, Dunstan DW. Screen-based entertainment time, all-cause mortality, and cardiovascular events: population-based study with ongoing mortality and hospital events follow-up. J Am Coll Cardiol. 2011;57(3):292-9.

3. Dunstan DW, Barr EL, Healy GN, Salmon J, Shaw JE, Balkau B, Magliano DJ, Cameron AJ, Zimmet PZ, Owen N. Television viewing time and mortality: the Australian Diabetes, Obesity and Lifestyle Study (AusDiab). Circulation. 2010;121(3):384-91.

4. Matthews CE, George SM, Moore SC, Bowles HR, Blair A, Park Y, Troiano RP, Hollenbeck A, Schatzkin A. Amount of time spent in sedentary behaviors and cause-specific mortality in US adults. Am J Clin Nutr. 2012;95:437-45.

5. Keadle SK, Moore SC, Sampson JN, Xiao Q, Albanes D, Matthews CE. Causes of Death Associated With Prolonged TV Viewing: NIH-AARP Diet and Health Study. Am J Prev Med. 2015;49(6):811-21.

6. Mora S, Cook N, Buring JE, Ridker PM, Lee IM. Physical activity and reduced risk of cardiovascular events: potential mediating mechanisms. Circulation. 2007;116(19):2110-8.

7. Hamer M, Stamatakis E. Physical activity and risk of cardiovascular disease events events: inflammatory and metabolic mechanisms. Med Sci Sports Exerc. 2009;41:1206-11.

8. Stamatakis E, Hamer M, Mishra GD. Early adulthood television viewing and cardiometabolic risk profiles in early middle age: results from a population, prospective cohort study. Diabetologia. 2012;55:311-20. 
9. Wijndaele K, Healy GN, Dunstan DW, Barnett AG, Salmon J, Shaw JE, Zimmet PZ, Owen N. Increased cardiometabolic risk is associated with increased TV viewing time. Med Sci Sports Exerc. 2010;42:1511-8.

10. Howard BJ, Balkau B, Thorp AA, Magliano DJ, Shaw JE, Owen N, Dunstan DW. Associations of overall sitting time and TV viewing time with fibrinogen and $\mathrm{C}$ reactive protein: the AusDiab study. Br J Sports Med. 2015 Feb;49(4):255-8.

11. Hamer M, Smith L, Stamatakis E. Prospective association of TV viewing with acute phase reactants and coagulation markers: English Longitudinal Study of Ageing. Atherosclerosis. 2015 Apr;239(2):322-7.

12. Wennberg P, Gustafsson PE, Howard B, Wennberg M, Hammarström A. Television viewing over the life course and the metabolic syndrome in mid-adulthood: a longitudinal population-based study. J Epidemiol Community Health. 2014 Oct;68(10):928-33.

13. Helajärvi H, Pahkala K, Heinonen OJ, Juonala M, Oikonen $M$, Tammelin T, Hutri-Kähönen $N$, Kähönen M, Lehtimäki T, Mikkilä V, Viikari J, Raitakari OT. Television viewing and fatty liver in early midlife. The Cardiovascular Risk in Young Finns Study. Ann Med. 2015;47(6):519-26.

14. Steptoe A, Breeze E, Banks J, Nazroo J. Cohort Profile: The English Longitudinal Study of Ageing. Int J Epidemiol 2013; 42:1640-48.

15. Hamer M, Stamatakis E. Screen-based sedentary behavior, physical activity, and muscle strength in the English longitudinal study of ageing. PloS One 2013; 8:e66222.

16. Hamer M, Lavoie KL, Bacon SL. Taking up physical activity in later life and healthy ageing: the English longitudinal study of ageing. Br J Sports Med 2014; 48:239-243.

17. Hamer M, Stamatakis E. Prospective study of sedentary behavior, risk of depression, and cognitive impairment. Med Sci Sports Exerc 2014;46:718-23

18. Hamer M, de Oliveira C, Demakakos P. Non-Exercise Physical Activity and Survival: English Longitudinal Study of Ageing. Am J Prev Med. 2014;47:452-60. 
19. Graig R, Deverill C, Pickering K. Quality control of blood, saliva and urine analytes. In: K. Spronston and J. Mindell, Editors, Health survey for England 2004, Methodology and documentation Vol. 2, The Information Centre, London, 2006, pp. 34-41.

20. Irwin $\mathrm{M}$, Artin $\mathrm{KH}, \mathrm{Oxman} \mathrm{MN}$. Screening for depression in the older adult: criterion validity of the 10-item Center for Epidemiological Studies Depression Scale (CES-D). Arch Intern Med. 1999;159:1701-4.

21. Katz S, Downs TD, Cash HR, Grotz RC. Progress in development of the index of ADL. The Gerontologist 1970; 10:20-30.

22. Friend DM, Devarakonda K, O’Neil TJ, et al. Basal Ganglia Dysfunction Contributes to Physical Inactivity in Obesity. Cell Metabolism. 2017;25(2):312-321.

23. Biddle SJ, Bennie JA, Bauman AE, Chau JY, Dunstan D, Owen N, Stamatakis E, van Uffelen JG. Too much sitting and all-cause mortality: is there a causal link? BMC Public Health. 2016;16:635.

24. Pedersen BK. Exercise-induced myokines and their role in chronic diseases. Brain Behav Immun. 2011;25: 811-16.

25. Latouche C, Jowett JB, Carey AL, Bertovic DA, Owen N, Dunstan DW, Kingwell BA. Effects of breaking up prolonged sitting on skeletal muscle gene expression. J Appl Physiol. 2013;114: 453-60.

26. Howard BJ, Fraser SF, Sethi P, Cerin E, Hamilton MT, Owen N, Dunstan DW, Kingwell BA. Impact on hemostatic parameters of interrupting sitting with intermittent activity. Med Sci Sports Exerc. 2013;45:1285-91.

27. Edwardson CL, Gorely T, Davies MJ, Gray L, Khunti K, Wilmot EG, Yates T, Biddle SJ. Association of sedentary behaviour with metabolic syndrome: a meta-analysis. PLoS One. 2012;7(4):e34916. 
28. Zethelius B, Berglund L, Sundström J, Ingelsson E, Basu S, Larsson A, Venge P, Arnlöv J. Use of multiple biomarkers to improve the prediction of death from cardiovascular causes. N Engl J Med. 2008;358(20):2107-16.

29. Lader D, Short S, Gershuny J. The time use survey, 2005 - how we spend our time. A report on research using the ONS Omnibus Survey produced on behalf of the Economic and Social Research Council (ESRC), Department of Culture, Media and Sport (DCMS), Department for Education and Skills (DfES), Department of Health (DH), Department for Transport (DfT), Office for National Statistics (ONS). 2006.

http://www.timeuse.org/files/cckpub/lader short and gershuny 2005 kight diary.pdf

30. Clark BK, Sugiyama T, Healy GN, Salmon J, Dunstan DW, Owen N. Validity and reliability of measures of television viewing time and other non-occupational sedentary behaviour of adults: a review. Obes Rev 2009; 10: 7-16.

31. Thorp AA, McNaughton SA, Owen N, Dunstan DW. Independent and joint associations of TV viewing time and snack food consumption with the metabolic syndrome and its components; a cross-sectional study in Australian adults. Int J Behav Nutr Phys Act. 2013 Aug 9;10:96.

32. Danesh J, Wheeler JG, Hirschfield GM, Eda S, Eiriksdottir G, Rumley A, Lowe GD, Pepys MB, Gudnason V. C-reactive protein and other circulating markers of inflammation in the prediction of coronary heart disease. N Engl J Med. 2004;350: 1387-97.

33. Smith L, Gardner B, Hamer M. Childhood correlates of adult TV viewing time: a 32-year follow-up of the 1970 British Cohort Study. J Epidemiol Community Health. 2015;69(4):30913.

34. Schmid D, Leitzmann MF. Television viewing and time spent sedentary in relation to cancer risk: a meta-analysis. J Natl Cancer Inst. 2014;106(7). 
Table 1. Descriptive characteristics of the sample at baseline.

\begin{tabular}{|c|c|c|c|c|c|}
\hline & $\begin{array}{l}<2 \mathrm{hrs} / \mathrm{d} \\
(\mathrm{n}=877)\end{array}$ & $\begin{array}{l}2<4 \mathrm{hrs} / \mathrm{d} \\
(\mathrm{n}=2833)\end{array}$ & $\begin{array}{l}<6 \mathrm{hrs} / \mathrm{d} \\
(\mathrm{n}=2279)\end{array}$ & $\begin{array}{l}\geq 6 \mathrm{hrs} / \mathrm{d} \\
(\mathrm{n}=2462)\end{array}$ & p-value ${ }^{c}$ \\
\hline Age (mean [SD] yrs) & $63.3 \pm 10.1$ & $64.1 \pm 9.9$ & $65.6 \pm 9.8$ & $65.4 \pm 9.9$ & $<0.001$ \\
\hline Men (\%) & 51.0 & 46.8 & 42.5 & 40.9 & $<0.001$ \\
\hline Current smokers (\%) & 6.4 & 10.9 & 12.6 & 18.8 & $<0.001$ \\
\hline Physically active $^{\text {a }}$ (\%) & 44.0 & 37.2 & 27.6 & 22.1 & $<0.001$ \\
\hline $\begin{array}{l}\text { Regular alcohol } \\
\text { intake }^{\text {b }}(\%)\end{array}$ & 70.0 & 68.4 & 58.4 & 54.2 & $<0.001$ \\
\hline $\begin{array}{l}\text { At least one chronic } \\
\text { illness (\%) }\end{array}$ & 45.6 & 47.8 & 55.7 & 59.5 & $<0.001$ \\
\hline Depression (\%) & 12.0 & 9.7 & 12.6 & 18.5 & $<0.001$ \\
\hline Disability (\%) & 18.1 & 18.4 & 24.8 & 33.7 & $<0.001$ \\
\hline $\begin{array}{l}\text { Obesity (\%) (BMI } \geq 30 \\
\mathrm{~kg} / \mathrm{m}^{2} \text { ) }\end{array}$ & 17.3 & 26.3 & 34.2 & 38.3 & $<0.001$ \\
\hline $\begin{array}{l}\text { HDL-cholesterol } \\
(\mathrm{mmol} / \mathrm{l})\end{array}$ & $1.66 \pm 0.45$ & $1.58 \pm 0.42$ & $1.56 \pm 0.41$ & $1.52 \pm 0.40$ & $<0.001$ \\
\hline Triglycerides (mmol/l) & $1.52 \pm 0.88$ & $1.67 \pm 0.96$ & $1.72 \pm 0.93$ & $1.78 \pm 1.00$ & $<0.001$ \\
\hline HbA1C (\%) & $5.76 \pm 0.42$ & $5.81 \pm 0.62$ & $5.89 \pm 0.68$ & $5.95 \pm 0.77$ & $<0.001$ \\
\hline $\begin{array}{l}\text { Log C-reactive protein } \\
(\mathrm{mg} / \mathrm{l})\end{array}$ & $0.95 \pm 0.66$ & $1.08 \pm 0.68$ & $1.24 \pm 0.74$ & $1.28 \pm 0.74$ & $<0.001$ \\
\hline Fibrinogen $(\mathrm{g} / \mathrm{l})$ & $3.21 \pm 0.54$ & $3.29 \pm 0.52$ & $3.40 \pm 0.54$ & $3.43 \pm 0.57$ & $<0.001$ \\
\hline $\begin{array}{l}\text { Systolic Blood } \\
\text { Pressure }(\mathrm{mmHg})\end{array}$ & $129 \pm 16$ & $132 \pm 17$ & $133 \pm 17$ & $134 \pm 18$ & $<0.001$ \\
\hline Prevalent CVD & 22.2 & 23.9 & 27.7 & 31.1 & $<0.001$ \\
\hline Prevalent cancer & 7.4 & 6.8 & 7.9 & 7.1 & 0.40 \\
\hline
\end{tabular}

Continuous variables are presented as mean \pm SD and categorical variables as $\%$.

${ }^{a}$ defined as vigorous intensity activity at least once per week.

${ }^{b}$ defined as alcohol intake at least once per week.

c $p$-values reflect differences across groups, examined using Chi-squared tests for categorical variables and ANOVA for continuous data. 
Table 2. Cox proportional Hazards regression for association between TV viewing and mortality $(n=8,451)$

\begin{tabular}{|c|c|c|c|c|}
\hline TV exposure & Deaths/N & $\begin{array}{l}\text { Model } 1 \\
\text { HR }(95 \% \mathrm{Cl})\end{array}$ & $\begin{array}{l}\text { Model } 2 \\
\text { HR }(95 \% \mathrm{Cl})\end{array}$ & $\begin{array}{l}\text { Model } 3 \\
\text { HR }(95 \% \mathrm{Cl})\end{array}$ \\
\hline$<2 \mathrm{hr} / \mathrm{d}$ & $21 / 877$ & 1.0 (Ref) & 1.0 & 1.0 \\
\hline $2<4 \mathrm{hr} / \mathrm{d}$ & $104 / 2833$ & $1.55(0.97,2.48)$ & $1.63(1.02,2.61)$ & $1.64(0.96,2.81)$ \\
\hline $4<6 \mathrm{hr} / \mathrm{d}$ & $95 / 2279$ & $1.62(1.01,2.59)$ & $1.49(0.92,2.39)$ & $1.66(0.97,2.84)$ \\
\hline$\geq 6 \mathrm{hr} / \mathrm{d}$ & $150 / 2462$ & $2.49(1.58,3.93)$ & $1.98(1.25,3.15)$ & $2.00(1.18,3.39)$ \\
\hline Per SD increase ${ }^{a}$ & & $1.26(1.15,1.38)$ & $1.17(1.06,1.28)$ & $1.18(1.05,1.33)$ \\
\hline
\end{tabular}

Model 1; adjusted for age and sex.

Model 2; adjusted for age, sex, physical activity, smoking, alcohol intake, depressive symptoms, long standing illness, disability (ADLs/IADLs)

Model 3; adjusted for same covariates in model 2 after removal of 72 deaths in first year of follow up.

${ }^{\mathrm{a}}$ Treated as a standardised score (1 SD=4.2 hrs/d TV viewing) 
Table 3. Cox proportional Hazards regression for association between biological risk factors and mortality ( $n=5,033 ; 149$ deaths).

\begin{tabular}{|l|l|l|}
\hline Risk factor & $\begin{array}{l}\text { Model 1 } \\
\text { HR per SD }\end{array}$ & $\begin{array}{l}\text { Model 2 } \\
\text { HR per SD (95\% CI) }\end{array}$ \\
\hline HDL-Cholesterol & $0.75(0.62,0.91)$ & $0.82(0.66,1.02)$ \\
\hline HbA1C & $1.14(0.98,1.32)$ & $1.04(0.89,1.23)$ \\
\hline Triglycerides & $1.08(0.91,1.28)$ & $1.03(0.86,1.25)$ \\
\hline Log C-reactive protein & $1.34(1.22,1.46)$ & $1.13(0.99,1.29)$ \\
\hline Fibrinogen & $1.60(1.39,1.85)$ & $1.40(1.16,1.68)$ \\
\hline
\end{tabular}

Model 1 adjusted for age, sex, BMI

Model 2 adjusted for age, sex, BMI, and mutually for other risk factors presented.

${ }^{a}$ Standard deviation (SD) for each risk factor was: HDL-Cholesterol $(0.42 \mathrm{mmol} / \mathrm{l}) ; \mathrm{HbA1C}(0.69 \%)$;

Triglycerides $(0.96 \mathrm{mmol} / \mathrm{l})$; log C-reactive protein $(0.27 \mathrm{mg} / \mathrm{l})$; Fibrinogen $(0.55 \mathrm{~g} / \mathrm{l})$ 
Table 4. Biological mediation analyses containing sub-sample from nurse visit $(n=5,033)$

\begin{tabular}{|l|l|l|l|l|}
\hline & Basic model $^{\mathrm{a}}$ & Basic + & ${\text { Basic }+ \text { metabolic }^{\mathrm{c}}}$ & ${\text { Final } \text { model }^{\mathrm{d}}}^{\text {inflammatory }}{ }^{\mathrm{b}}$ \\
\hline $\begin{array}{l}\text { All cause mortality } \\
\text { (149 events) }\end{array}$ & & & & \\
\hline HR per SD unit \\
\hline In HR & $1.24(1.07,1.44)$ & $1.20(1.04,1.39)$ & $1.24(1.07,1.44)$ & $1.21(1.05,1.41)$ \\
\hline $\begin{array}{l}\text { CVD mortality } \\
\text { (29 events) }\end{array}$ & 0.217 & 0.183 & 0.218 & 0.194 \\
\hline HR per SD unit & $1.50(1.11,2.03)$ & $1.44(1.06,1.95)$ & $1.51(1.11,2.05)$ & $1.43(1.06,1.95)$ \\
\hline In HR & 0.404 & 0.361 & 0.412 & 0.361 \\
\hline
\end{tabular}

adjusted for age, sex, physical activity, smoking, alcohol intake, depressive symptoms, long standing illness, disability (ADLs/IADLs), body mass index, systolic blood pressure.

${ }^{\mathrm{b}}$ Basic model (as above) with additional adjustment for log C-reactive protein and fibrinogen.

'Basic model with additional adjustment for $\mathrm{HbA1C}, \mathrm{HDL}-\mathrm{C}$, triglycerides.

${ }^{d}$ Final model adjusted for age, sex, physical activity, smoking, alcohol intake, depressive symptoms, long standing illness, disability (ADLs/IADLs), body mass index, systolic blood pressure, log C-reactive protein, fibrinogen, $\mathrm{HbA1C}$, HDL-C, triglycerides.

${ }^{\mathrm{e}}$ Hazard ratio (HR) for TV viewing modelled continuously per SD increase (4.2 hrs/d) 